\title{
Novel Metaphor and Conceptual Stability
}

\author{
(Metáfora Nova e Estabilidade Conceptual)
}

Helena MARTINS

(Pontificia Universidade Católica do Rio Janeiro)

\begin{abstract}
This paper discusses three radically different approaches to the issue of novel metaphor: the classic view, according to which metaphor is itself defined by its novelty with respect to our established conceptual systems; the cognitivist view, in which novel conceptual metaphors are considered a possible but relatively rare phenomenon; and the deconstructionist view, in which novelty in metaphor is seen as either impossible or a non-issue. The possibility of reconciling valuable insights yielded in each of these approaches is explored, and the case is made for taking the matter under a nonrepresentationalist, Wittgensteinian angle.
\end{abstract}

KEY-WORDS: novel metaphor, conceptual stability, representationalism, Wittgenstein.

RESUMO: Este trabalho discute três abordagens radicalmente diferentes para a questão da metáfora nova: a visão clássica, segundo a qual a metáfora é definida pela sua novidade em relação a sistemas conceituais estabelecidos; a visão cognitivista, em que metáforas conceituais novas são consideradas um fenômeno possível mas relativamente raro; e a visão desconstrucionista, em que a novidade na metáfora é vista como impossivel ou uma não-questão. A possibilidade de se reconciliar reflexões valiosas provenientes de cada uma dessas abordagens é explorada e a proposta de se abordar o problema a partir de uma perspectiva wittgensteiniana é defendida.

PALAVRAS-CHAVE: metáfora nova, estabilidade conceptual, representacionismo, Wittgenstein.

This paper addresses the issue of novel metaphor. My discussion will be centered around the possibility of conceptual novelty in metaphor, around what has once been described by Lakoff and Turner (1989:51) as "the attempt to step outside the ordinary ways we think metaphorically $[\ldots]$ to offer new modes of metaphorical thought". If novel metaphor is taken 
from this angle - in terms of its status with respect to our established conceptual systems -, then at least three important and well-known theoretical views show up for consideration. Let us begin by briefly recalling them.

\section{Three perspectives on novel metaphor}

In Paul Ricoeur's by now classic The Rule of Metaphor, we find a qualified defense of the traditional idea that novelty or deviation with respect to our established conceptual systems is a property that defines metaphor itself. In a paper published a few years after this book, he sums up this position when, referring to metaphor, he says:

"It is as if a change of distance between meanings occurred within a logic space. [...]

Things or ideas that were once remote from each other become close" (1992: 147).

Within his view, shared with a considerable number of metaphorologists, it is characteristic of metaphor that this "new semantic pertinence", to use the author's words, resists conceptual stabilization. Should a metaphor become conventionalized in our conceptual systems, this would correspond to its death - and as Ricoeur says, echoing the position of many other scholars, "dead metaphors are no longer metaphors, but instead are associated with literal meaning" (Ricoeur, 1975:290; see also, for example, Black, 1993; Kittay 1987; Fogelin 1994).

One first kind of position on the issue of novel metaphor is then the idea that novelty with regard to our established conceptual systems defines metaphor, being indeed metaphor's only possibility of existence.

A radically different but equally important way of viewing the issue of novel metaphor is to be found in Lakoff \& Johnson's seminal work on metaphor within the framework of Cognitive Linguistics (cf. Lakoff \& Johnson 1980, Lakoff 1993, Lakoff \& Johnson 1999) ${ }^{1}$. About novel metaphor, Lakoff says:

\footnotetext{
1 The framework I address in this paper has come to be known as "Conceptual Metaphor Theory" (CMT). As Grady, Oakley \& Coulson (1997) point out, CMT is to be distinguished from "Blending Theory" (BT), a more recent development in Cognitive Linguistics, with many important implications to the analysis of metaphor. We assume here, as Grady, Oakley \& Coulson do (p. 101-2), that BT does not replace CMT, and that the two approaches are complementary.
} 
"metaphor resides in this huge, highly structured, fixed system, a system anything but 'dead'. [... . Novel metaphor uses this system, and builds on it, but only rarely occurs independently of it" (1993:228)

On this account, autonomy from our established conceptual systems, far from being a defining property of metaphor, is recognized as something that only rarely takes place. The novelty of novel metaphor is itself downplayed, the emphasis falling into its dependence with respect to our conventional conceptual systems (cf. Lakoff \& Turner, 1989). From the point of view of what interests us most in the present discussion - which is the possibility of stepping outside our ordinary ways of thinking metaphorically -, let us register, then, that a second important position here is the one which states that novelty in metaphor is possible - but rare.

Finally, a third way of viewing the issue novel metaphor which deserves our attention is the one we find in deconstructionist approaches, such as that of Jacques Derrida $(1972,1978)$ and Paul de Man (1992). In an oftenquoted passage of "White Mythology", Derrida says:

"The movement of metaphorization (the origin and then the effacing of the metaphor, the passing from a proper sensible meaning to a proper spiritual meaning through a figurative detour) is nothing but a movement of idealization” (p. 25)

Following an avenue opened by Nietzsche, Derrida radicalizes the role of metaphor in the formation of human concepts in general. Equated to metaphorization, concept formation is itself viewed as a "movement of idealization". In this sense, our so-called established concepts would be, to borrow Nietzsche's famous words, no more than "illusions which one has forgotten they are illusions" ${ }^{2}$. From this viewpoint, arguably, if our established concepts are illusory, so will be any alleged novelty with respect to these concepts - any new insight that may be attributed to a novel metaphor will itself be deemed an illusion. By calling into question the very opposition between what is metaphorical and what is nonmetaphorical, Derrida is indirectly also calling into question the opposition between old and new metaphor. One could say, then, that from a deconstructionist viewpoint, novelty in metaphor is either impossible or a non-issue.

2 "On Truth and Lie in an Extra-Moral Sense", §1. 
We are thus confronted with three very different angles on novel metaphor: depending on the one we pick, novel metaphor may be viewed as the only possibility, possible but rare, or impossible.

A legitimate question at this point would be: but are these three views even commensurable? Are these people even talking about the same thing in their considerations about metaphor and novel metaphor? Underlying such heterogeneous range of views on novel metaphor, we are surely going to find very diverse theories of metaphor, and very diverse theoretical points of view on the relationship between metaphor, language, and thought. Actually, the authors mentioned above are sometimes very explicit and emphatic in denying the adequacy of each other's theories. Both Ricoeur and Lakoff, for example, invest explicitly against Derrida's approach (cf. Lakoff, 1993:248-29; Ricoeur 1975: Chap. 8).

Particularly at stake here is of course the stand one is prepared to take on such interrelated matters as that of the autonomy of metaphor from language, and that of the autonomy of metaphor from our established conceptual systems. The positions here vary so wildly, that one is entitled to doubt whether the three perspectives can indeed be compared on any common grounds or standards. ${ }^{3}$ I am convinced, however, that there is a sense in which these three approaches do say something about the same thing - namely about the possibility of novelty with respect to our established conceptual systems and about the role of metaphor in the context of this possibility. But even accepting that the three views are comparable on a common ground, one is still entitled to ask why bother comparing them. The reason I have for bringing them together for consideration here is my belief that they all hold valuable, indispensable insights with regard to the topic of this paper - novel metaphor and conceptual stability. In what follows, the possibility of a fruitful reconciliation of these insights is explored on a preliminary basis.

\footnotetext{
3 A particularly sensitive point of dissent that is not directly focused on here is that of the locus of metaphor: classic theories, like Ricoueur's, tipically locate metaphor in language as a prompter for thought, whereas cognitive theories generally locate it in thought, viewing linguistic manifestations of metaphor as mere reflexes of cognitive realities and processes. Deconstructionist approaches, in turn, definitely locate metaphor in language, but regarding language as the very fabric of human thought and existence. In using the term metaphor throughout the paper with respect to these three different perspectives, I will, most of the times, deliberately bypass this discussion, though it is important that these differences are acknowledged. Section 3 clarifies my position on the issue.
} 
Two steps are necessary in this exploration: first, to state some of the insights that are found particularly valuable in each of the three approaches under consideration; and second, to indicate a general view of language and meaning that is capable of accommodating these insights, despite their origin in such diverse theoretical frameworks.

\section{Insights on novel metaphor}

Let us consider the first position examined here - namely that novelty or autonomy with respect to our established conceptual systems is the only possibility for metaphor. Theories of such persuasion tend to emphasize the irreducibility of metaphorical meaning, its resistance to conceptual stabilization, its incapacity to yield cognitively stable results. The movement of metaphor towards concept would be, as we have seen, its movement towards its own death. In this spirit, Paul Ricoeur says that the "semantic shock" engendered by metaphor "produces a conceptual need but not as yet any knowledge by means of concept", suggesting that, in metaphor, "the gain in meaning is not carried to the concept" (1975:296). In the same vein, Samuel Levin claims that "the effort to achieve interpretive consummation [in metaphor] is doomed, ultimately, to failure" (1988:24). And Max Black warns us "against the danger of postulating a standard response to a given metaphorical statement - a response determined by linguistic, conceptual, cultural, or other conventions" (1993:24). What is interesting here is that, cautious as they are in warning us that metaphors do not engender stable cognitive results, determined as they are in insisting that metaphors are incapable of promoting any kind of conceptual peace , these authors all seem to agree that this absolutely does not mean that metaphors are so to speak cognitively empty.

How so? To understand this point one has to acknowledge these authors' refusal to equate cognitive gain with the production of specific concepts. Max Black describes the possibility of cognitive gain without concept production, by suggesting that metaphors do not actually say anything about reality; they do not translate anything that could be captured as a concept represented by language - rather than saying anything, they "show us how things stand" (1993:39). For him, metaphors do not create referents, but perspectives. An analogous view can be recognized in Levin's idea that metaphors produce conceptions rather than concepts (1988:91); and also in 
Ricoeur's idea that the cognitive gain yielded by metaphor is a sort of, in his words, "especial attunement with aspects of reality" (1992:145).

I believe that these authors have a good point both when they call our attention to the special resistance to conceptual stabilization that novel metaphor (for them, metaphor tout court) tend to show, and when they warn us against the dangers of postulating standard responses to a given novel metaphorical statement. I also think there is insight in recognizing the possibility of cognitive gain without the production of specific concepts.

What seems to me inadequate in this approach is the idea that novelty or autonomy with respect to our established conceptual systems is a precondition for metaphor in general. And here, naturally, we turn to the second view brought to consideration here, namely the cognitivist view that novel metaphor is a possible but relatively rare phenomenon.

The wealth of arguments and generalizations that have been produced within the framework of Cognitive Linguistics since the 80's speaks eloquently in favor of the recognition of the crucial role played by perfectly conventional conceptual metaphors in the way we live, act and think metaphors which, as cognitivists say, are anything but dead. No contemporary theory of metaphor can afford to ignore the arguments and generalizations over metaphor that have been and still are being produced within this model. Moreover, the empirical studies and descriptions of our conventional metaphorical conceptual systems conducted within this model are extremely illuminating, in that they give us insight not only into the nature of metaphorical processes, but also into the possibilities and implications of different human modes of existence, and of different human cultural practices (the by now classic list of references here includes Lakoff \& Johnson, 1980, 1999; Lakoff 1987, 1993; Sweetser, 1991; Lakoff \& Turner, 1989; Turner, 1996). Specifically with respect to novel metaphor, there is insight, I believe, in the idea that conventional metaphors may be extended in novel ways, there existing a fundamental unity in metaphor between what is seen as conventional and what is perceived as new.

However, when we turn to Lakoff s idea that entirely novel conceptual metaphors are a possible but relatively rare phenomenon, some important questions may suggest themselves. We may begin to wonder if this way of putting the matter doesn't indicate a perhaps overly fixing and overly reifying understanding of our established conceptual systems. To begin 
with, given the overall appearance of the cognitive model, it is not entirely clear in what sense a metaphor can actually be seen as independent from our established conceptual systems. A few words on this overall appearance may come in hand here.

In the Cognitive Linguistics tradition, metaphors are viewed as mental mappings across conceptual domains, occurring, as we have seen, in a "huge, highly structured, fixed system" (Lakoff 1993:228). The conceptual systems where metaphors occur are, moreover, seen as regularly motivated, as ultimately grounded in some universal, non-propositional, preconceptual structures of experience - notably, "image schemas" and "basic level categories" (cf. Lakoff, 1987; Johnson 1987). What is frequently referred to as "direct experience" is supposed to be the ultimate source of virtually all metaphors in our conceptual systems; some of these metaphors are indeed so closely linked to this primary level of experience as to be considered universal themselves. ${ }^{4}$ Concepts that emerge from this so-called direct experience are, in short, experiential universals that would ultimately define "the range of possible patterns of reason and understanding" (Johnson, 1987:137). They would, as M. Turner puts it, "migrate intact through historical and anthropological boundaries" (Turner, 1996:11).

That most of the concepts presented as instances of such experiential universals are of an at least controversial universality is something that reflects itself in the cautious qualifications that recur whenever they are mentioned in the cognitive literature - Lakoff himself seems to admit that they are more in the realm of plausible accounts than in that of scientific established generalizations. ${ }^{5}$ Moreover, dissatisfaction with candidates to universality presented in the cognitive literature has led to criticism coming from a variety of authors and perspectives (see, for example, Kittay, 1987; McCormac, 1990; and Rakova, 2002).

In any case, if such controversial concepts do define the range of possible patterns of reason and understanding, then it is not entirely clear how a

\footnotetext{
4 According to Lakoff \& Johnson, these primary metaphors would be embodied, in the sense of being basic recurrent patterns of our bodily experiences with the world, that would eventually become encoded in our neural systems (cf. Lakoff \& Johnson, 1999, 2002).

5 Referring once to a "candidate for a metaphorical universal", he suggests, for instance, that it is one among other conceptual metaphors that "appear to be universal, or at least very widespread" (Lakoff, 1993:249, my emphasis).
} 
metaphorical concept can ever occur independently of it. ${ }^{6}$ The possibility of independence is, however, acknowledged in the cognitive theory of metaphor: recall the already quoted allusion Lakoff \& Turner make to the possibility of stepping outside the ways we think metaphorically and create new modes of metaphorical thought (see also Gibbs, 1994.255).

Although they have their existence admitted, those entirely novel metaphors have not received much attention in the cognitive model, possibly in virtue of its alleged rarity. But the admission of their existence, however rare, poses a certain risk to the cognitivist hypothesis that our conceptual systems are regularly motivated, systematically grounded in universal structures of our experience. For it is possible that the analysis of such singular original metaphors turns out to reveal that they in fact originate structure in our conceptual systems - novel metaphors may after all become conventionalized. If they are created independently of these systems, if they can inaugurate entirely new mappings between domains, this could theoretically introduce the possibility of motivating but unmotivated structures in our conceptual systems. Which is something that would have the potential to make us rethink the foundational basis of conceptual systems as they are proposed in cognitive approaches.

To sum up, what seems to me insightful in the cognitive approach is, first, the way it demonstrates the massive influence of metaphor in our forms of action and thought, and second, the way it shows that there is basic unity between more and less conventional metaphors. What does not seem so adequate, on the other hand, is the idea that the allegedly "rare" metaphors that cannot be explained as a derivation from our established conceptual systems - conceived as universally grounded mental realities - should be considered "independent" of these systems.

At this point, we are more or less naturally brought to the third and last position examined here, namely the deconstructionist view of novel metaphor as either impossible or a non-issue. Deconstructionism can be seen as a philosophical approach which follows a certain historical propensity in contemporary philosophy, namely that of a reaction to foundationalism

\footnotetext{
6 The hypothesis is unclear even in the case of image metaphors, a common example of independent conceptual metaphor given in the cognitive literature (cf. Lakoff, 1993:229-21; Martins, 1999:101-112)
} 
and essentialism - a reaction to the very project of determining a universal basis for knowledge and truth. Anti-essentialism and anti-foundationalism have indeed been described by Richard Rorty as "the main point of convergence between analytical e continental philosophy", approximating philosophers such as Heidegger, Wittgenstein, Derrida, Foucault, Austin, and many other authors whose lines of argumentation and styles of thinking are otherwise very diverse (cf. Rorty, 1991:99).

In the context of our discussion here, Derrida's anti-foundationalist approach to metaphor can be seen as an unlikely and disquieting synthesis of the two positions described earlier: it will simultaneously insist in the cognitivist idea that we live by metaphors and in the classic idea that metaphor resists conceptual stability. How so? By suggesting that our metaphors, even those that are highly conventionalized, are not grounded anywhere - that the so-called stability of our conceptual systems is nothing but a desire of stability, a desire that yields arbitrary symbolic creations, distortions and anthropomorphic simplifications which are essentially contingent and fragile, but without which we don't seem to be able to live (cf. Arrojo \& Rajagopalan, 1992; Culler 1989).

Derrida's line of thought on this subject is of course much deeper and much more complex than this brief allusion to his philosophy may suggest (see Derrida 1978, 1982). Equally deep and complex is the host of conceptual arguments and rationales offered by many other authors in contemporary anti-foundationalist philosophy (cf. Solomon 1988; Rorty 1991; Cavell 1996). If one is inclined, as I am, to yield to the weight of these arguments, one may as well be inclined to go along with Derrida when he questions the stability and transparency of our so-called established conceptual systems, and the line that separates old and new metaphor.

However, as I intended to show elsewhere, by doing so, one does not necessarily have to accept the kind of anti-theoretical nihilism that often comes hand in hand with anti-foundationalist approaches (cf. Martins, 1999: section 3.1).

Under a strict anti-foundationalist perspective, the studies conducted in Cognitive Linguistics would, for example, be viewed at best as uninteresting, and at worst as plainly wrong on account of their foundational commitments. As I said, however, I find these studies highly revealing and instructive - I think they do tell us very important things about ourselves, 
by revealing facts about the languages of the world. It is noteworthy here that Nietzsche, of all predecessors of Deconstructionism, was himself a philologist. Nietzsche, for whom "there were no facts, only interpretations" apparently was himself very much interested in the "facts" of language. The intellectual practice of this philosopher, if not his explicit theoretical views, speaks for the fertility of reconciling a non-foundationalist philosophical stance with an interest in empirical angles on language.

The possibility of reconciliation of these and other perspectives is indeed the object of my exploration here. At this point, thus, we can move on to the second step in this exploration, with the indication of a philosophical point of view which is capable of reconciling the insights that were found valuable in the three seemingly excluding positions examined above. Before doing so, however, it is convenient to sum things up.

What I would like to have is a perspective that could accommodate the idea that some metaphors may strike us a specially alien or novel with respect to our established conceptual systems having a special cognitive effect; and the idea that conventional conceptual metaphors influence the way we think and act; and the idea that there is a basic unity between what is taken to be conventional and what is taken to be novel in metaphor and the idea that metaphors, even conventional ones, have ultimately irreducible meanings and resist conceptual stabilization; and the idea that human conceptual systems as a whole have only a relative stability and transparency; and the idea that this does not preclude the possibility of a systematic and principled study of such systems through language analysis, notably metaphor analysis.

I would like to suggest the possibility that Wittgenstein's view of language as part of a form of life, rather than as an instrument of representation of thought or reality, might provide such a point of view. I believe the perspective offered in Wittgenstein's later philosophy allows us to see things under an interesting light, where the "autonomy of metaphor" issue can be recast, together with the notion of novel metaphor. ${ }^{7}$

\footnotetext{
7 Focus here will be mainly placed on the Philosophical Investigations [henceforth PI], with occasional allusions to The Blue and the Brown Books [henceforth BB], and On Certainty [henceforth OC]. For a presentation of Wittgenstein's conception of language as part of a form of life, see Cavell 1979: chapt. VII; Baker \& Hacker 1980:Chapt 1; Glock 1996:124-129).
} 


\section{Novel metaphor and conceptual stability: a Wittgensteinian approach}

As I mentioned before, Wittgenstein's philosophy - which I have of course no intention to summarize here - moves in roughly the same direction as many other contemporary philosophical theories, namely against traditional essentialism and foundationalism. And, like many other philosophers identified with the so-called "linguistic turn", Wittgenstein takes language as a starting point in his critique. Indeed, he seems to credit all sorts of philosophical "ailments" (e.g. solipsism and skepticism) to some abiding mistakes and misconceptions about language to be found in the history of Western Philosophy. Notable among these mistakes would be the commitment to a certain perspective that, being strongly based on the notion of representation, is often termed a representationalist view of language and meaning (cf. Baker \& Hacker, 1980, Introd.). In different versions and with different emphases, this view could be attributed to such influential and diverse philosophical systems as those of Plato, Aristotle, Locke, Frege, and many others (cf. Harris \& Taylor, 1989). The representationalist view amounts roughly to the assumption that language's primary and essential function is to represent extra-linguistic entities of some sort - real, mental, virtual, or whatever.

In the ingenious, if somewhat cryptic, passages of the Philosophical Investigations (as well as in most of Wittgenstein's later texts), we find an invitation to reconsider this traditional point of view - to confront it with a radically different perspective, in which language can no longer be taken as an abstract system that is grounded on - but separable from - reality or mind or culture. Under the Wittgensteinian view, language cannot be said to represent systems of concepts - for such systems have no autonomous existence themselves; they exist nowhere but in our own language-infused human practices. Language is thus regarded as a central factor in the organization of experience - it at the same time institutes and reflects our shared forms of life, an attunement in our criteria which is culturally and historically contingent (cf. PI $\S ~ 19,23,241$; Baker \& Hacker 1980: 47f; Glock 1996: 45-50).

The idea that our linguistic and non linguistic practices are inseparable and have mutually constitutive bonds - that language is not grounded anywhere outside itself - is emphasized by Wittgenstein as a way of calling 
into question the sort of foundational quest that seems to characterize traditional metaphysics. With his reflections on language, Wittgenstein aims at warning us against that "craving for generality" that is for him the source of so many embarrassments to thought and reason ( $B B$, p. 17). For the root of these embarrassments, as said before, is to be found exactly in a misguided picture of language, a picture that "surrounds the workings of language with haze that makes clear vision impossible" (PI, § 5). In the alternative path offered by Wittgenstein, it is the link between language and representation that one has to part with.

However, the defense of a non-representationalist view of language within the context of a critique to the foundational project of metaphysics is hardly an idiosyncrasy of Wittgenstein. As we have seen, the same general movement is to be found in many other contemporary philosophical theories, including those developed in deconstructionist approaches, mentioned above with respect to the issue of novel metaphor. What is then specific about Wittgenstein's anti-foundational viewpoint that makes it so especially eligible to reconcile the different insights on novel metaphor described in this paper? In what follows, I highlight a few points in Wittgenstein's conception of language that would have to be involved in an answer to this question.

A first key aspect that deserves attention here is that of conceptual stability. For recall that this paper focuses on the possibility of metaphor bringing up novelty with respect to our established conceptual systems. But if systems of concepts exist nowhere but in human praxis, then how established can these systems ever be? In other words, what kind of stability can be attributed to human concepts in face of the contingency of the practices they depend on? Central to a Wittgensteinian reassessment of the issue of novel metaphor is the adoption of what might be called a "non superlative" view of the stability of our shared conceptual systems (PI, $\S \S$ 97, 192).

Under this view, human conceptual systems enjoy the same kind of stability as that of the language-infused human practices with which they are interwoven - no more and no less. On the one hand, these practices are not governed by any kind of exterior principle, any kind of "super-rule" that would contain in itself all of its possible applications. Indeed, Wittgenstein urges us not to forget that the "language game is so to say 
something unpredictable" - for it is "not based on grounds. [...] It is not reasonable (or unreasonable). It is there - like our life." (On Certainty, §559). On the other hand, these practices are not at all deprived of stability: the omnipresence of the game analogy in the Philosophical Investigations suggests how central it is for Wittgenstein the idea that language - and the praxis from which it cannot be separated - is a rule-governed phenomenon.

But how can an activity be at the same time unpredictable and rulegoverned? According to Wittgenstein, this poses a problem only if we think - foundationally - that there is a gap between a rule and its application, if we fail to realize that rule following is essentially a practice. As Wittgenstein puts it: "to obey a rule, to make a report, to give an order, to play a game of chess, are customs (uses, institutions)" (PI §192). In other words, a rule does not exist unless there is a practice of calling some things "obeying a rule" and other things "going against it" (PI 201; cf. Glock: 323-329). For Wittgenstein, then, human conceptual systems are indeed stable and rule-governed: but they enjoy the changeable, flexible, potentially open stability of a game - and not the fixed, closed, and superlative regularity of a calculus (cf. PI $\S \S 81,559,565$ ).

A second important aspect of Wittgenstein's conception that deserves our attention here is closely related to the issue of stability: what kind of transparency is to be attributed to human conceptual systems, given their non-superlative stability? Here again, the answer is: the very same transparency that can be attributed to the praxis where these systems may be said to exist. The possibility of total transparency, of a complete and ultimate overview of our language practices and concepts, is explicitly denied by Wittgenstein (cf. PI $\S \S 68,88,120$; see also Cavell 1979:183-185). We cannot, so to speak, step outside our practices in order to survey them completely - the attempt to do this would indeed correspond to the misguided metaphysical impulse Wittgenstein tries to undermine. However, to say that this kind of absolute transparency is unattainable is not to say that our practices are utterly opaque, that we are so to speak following rules blindly, without having any idea whatsoever about them. We can and for different reasons we often do - provide explanations about our concepts. If these explanations can never be final or complete, it does not make them worthless. An explanation is a perfectly legitimate move in the language game, even though it can never be produced from outside the language game (cf. Cavell 1979:188; Glock 1996:47). 
This is an important point to make here, considering that, as said before, non-foundational approaches often come together with a sort of anti-theoretical nihilism that is to be avoided if one wishes, as I do, to grant importance to empirical studies of language and meaning. If one accepts that concepts are not fixed entities, it is indeed possible that one tends to view any attempt to provide explanations about concepts as a futile reificatory gesture, as the creation of an illusion, or something similar. The non-foundational stance does seem to license or even insinuate the idea that meaning is essentially beyond human control, and hence incompatible with any kind of description. However, if we take a Wittgensteinian point of view, we may be inclined to think that a reaction to the metaphysical thesis that meanings are fixed entities should not bring about the equally metaphysical conclusion that the partial explanations we are able to provide about them are merely illusory. For they would be illusory as compared to what? As Mulhall (1996:16) puts it, to draw this conclusion is "to participate in the very metaphysical impulse that one claims to overcome". An explanation of meaning is necessarily a reificatory gesture, but this gesture is not only a perfectly legitimate one, but also a potentially instructive and illuminating one, provided there are no "superlative" ambitions involved.

With his notion of an object of comparison, Wittgenstein renders this possibility especially clear. Explanations of meaning never characterize the phenomena, and yet they do determine a possible scheme for viewing them - as "objects of comparison", these explanations are supposed to "throw light on the facts of our language by way not only of similarities, but also of dissimilarities"; they are supposed to provide "an order in our knowledge of the use of language [...]; not the order" (PI §§ 130-132) The notions of explanation and object of comparison in Wittgenstein are extremely complex and resist synthesis (see Glock 1996:111-114; 278-283; Martins 1999: 136-147). With this brief allusion to them, however, I wish to emphasize the following point: the adoption of a non-foundational perspective does not preclude principled descriptions of human conceptual systems, through language analysis. Those systems have only a relative transparency and stability, but the creation of objects of comparison related to them can be potentially illuminating.

With respect to the specific topic of this paper, what is outlined here is a perspective where empirical studies about conceptual metaphors may 
indeed "throw light in the facts" of our language and cultural practices, even if they are not engaged in any sort of foundational quest. At his point, we can turn to consider more specifically how metaphors and novel metaphors are to be understood within this perspective.

To begin with, if concepts exist nowhere but in the (linguistically woven) fabric of "our complicated form of life" (PI, p. 174), there is obviously no room for any understanding of metaphor as an autonomous conceptual entity. A more plausible account would render metaphor itself as a kind of practice, namely the practice of intercrossing language games, that is, "of using the words of one language game according to rules of another" (Glock, 1996:196-197) ${ }^{8}$. In talking about intercrossing language games as a matter of "using words", it is vital that we bear in mind that, under a Wittgensteinan perspective, human existence is itself linguistically articulated, our linguistic and non linguistic practices having, as said before, mutually constitutive bonds.

Wittgenstein was himself very much interested in this kind of intercrossing practice, mostly because he saw it as one of the important sources of the philosophical "haze" he meant to dispel. So, he points out, for example, that

"To say that we are trying to express the idea which is before our mind is to use a metaphor, one which very naturally suggests itself; and which is all right as long as it doesn't mislead us when we are philosophizing" ( $B B$, p. 41$)$.

The point I wish to highlight in this passage is not so much the philosophical dangers that inhere in the practice of crossing language games, but rather the recognition of its naturalness by Wittgenstein. What is to be noted here is that the idea that perfectly conventional (natural) metaphors may influence the way we act and think is indeed compatible with a Wittgensteinian non-foundational picture of language and meaning. Now, it is reasonable to assume that, regardless of the specific concerns that led Wittgenstein to comment on such intercrossing language games, their

\footnotetext{
8 As Glock (1996:193-198) makes it clear, the notion of language game is extremely polysemic in Wittgenstein's texts. In this paper, I am using it to refer to actual linguistic activities described against the background of our non-linguistic practices (cf. PI $\S 23,249,363$; p. 224). Language games should not, however, as we shall see, be regarded as self-delimited indecomposable monads - fixed divisions in a territory of pre-determined linguistic and non-linguistic activities (cf. Barbosa Filho, 1973:76).
} 
occurrence is not bound to be associated with only one kind of (negative) effect; as we have seen, Wittgenstein himself hints at another sense in which they are "all right".

If seen as intercrossing language games, metaphors can indeed be regarded as having an indefinite number of possible repercussions, and wildly variable degrees of visibility. Thus, metaphors that are so entrenched in our forms of life as to go unnoticed by most of us, most of the times, may indeed have an impact not only on philosophical systems, as Wittgenstein observed, but on all sorts of human affairs, influencing the course of science, politics, social policies, art, education, medicine, personal relationships, and so on. On the other hand, there is always the possibility of intercrossing language games that may not go unnoticed by us at all, but, on the contrary, may strike us as very novel or alien with respect to our usual practices. These too can have many different kinds of repercussions. Notable among them is that of calling our attention to the "old" metaphors we live by, either to question them, or to praise them, or to elaborate them, or to subvert and replace them (cf. Lakoff \& Turner, 1989). This is of course only one among other possible repercussions associable to such unusual metaphors. What I hope to have made clear, in any case, is that intercrossing language games may be taken as more or less entrenched in our practices, with different possible effects and different possible degrees of visibility.

At this point, we arrive at a plausible characterization of novel metaphor under a Wittgensteinian viewpoint: novel metaphor may be associated with the possibility of unusual or unexpected intercrossing language games. Now, it is crucial to the understanding of this preliminary characterization that we pay due attention to some of the key aspects of Wittgenstein's picture of language and meaning that were highlighted here before. For if these points go unnoticed, this perspective may be mistaken for a mere notational variant of other approaches of metaphor, notably the cognitive approach mentioned above.?

\footnotetext{
9 It could be argued, for instance, that all there is to the Wittgensteinian alternative briefly outlined above is a replacement of the cognitivist expression "mappings between different conceptual domains" for the expression "crossings between different language games", with no theoretically substantive change whatsoever.
} 
More specifically, it is vital that we acknowledge the particular way Wittgenstein sees the relationship between what is "usual" and what is "unusual" in our "complicated" form of life. As we have seen, under his view, language, together with the human affairs with which it interweaves, is at the same time regular - in the sense that it both determines and is determined by reactions, practices, and behaviors that are considered normal in a community -, and irregular - in the sense that nothing exterior to these reactions and practices regulates what is to be considered normal and what is not. Language is, in the words of S. Cavell, at the same time tolerant and intolerant - just "as love is tolerant and intolerant of differences, as materials or organisms are of stress, as communities are of deviation, as arts or sciences are of variation" (1979:182). But how do we know for sure what is tolerable and what is not? The answer is: we don't. No absolute standards of tolerance and intolerance are ever made available - human practices have for us, as said before, only a relative transparency. This means that, at any given moment, one can never have a full notion of which moves in the language game are going to be considered legitimate, or normal, or expected - as we have seen, to an important extent, "the language game is so to say something unpredictable" (OC \$559). So, when we say that novel metaphor relates to unusual or unexpected intercrossing language games, we have to qualify this statement by adding that there are no absolute parameters available for us to determine what is usual and what is unusual. We have to bear in mind, hence, that, in an important sense, there is a fundamental unity between the most conventional and the least conventional metaphors.

Seen as intercrossing language games, metaphors - old or new - must conform to the tolerant-intolerant nature of human affairs and language; they all have to fit somehow into this unlimited yet rule-governed territory of human relations called "ordinary language" - a territory which can, of course, sometimes strike us as pretty extraordinary (cf. Perloff, 1996:57). There is no such thing, thus, as a metaphor that is independent or autonomous with respect to the established conceptual systems that may be said to live in our language-embedded human practices. Enjoying a non-superlative stability and transparency, these systems always include the possibility of the extraordinary within the ordinary. Hence, one cannot separate two distinct territories - that of the ordinary and that of the extraordinary. Moreover, given that metaphors are viewed as practices, and that there are no absolute standards to determine whether these practices are expected or unexpected, so, thus understood, metaphors cannot have their degree 
of novelty evaluated as an absolute inherent property, corresponding to some fixed status of autonomy or dependence in relation to established conceptual systems.

If we adopt the Wittgensteinian approach that I have been outlining here, instead of viewing metaphors as conceptual entities inherently characterized by their particular status with respect to our established conceptual systems, we should regard them rather as kinds of human practices, with different - and ultimately irreducible - possible effects and repercussions. This means that metaphors cannot be taken as transsubjective conceptual entities with an absolute, determinate meaning. The Wittgensteinian alternative view helps us to make sense of some more or less trivial facts that do not quite fit in a picture of metaphors as conceptual entities with inherent absolute properties, ultimately derived from a universal set of basic concepts: it explains, for example, why what is taken to be metaphoric in one culture or moment of history may not be taken so in another; why what is experienced as a novel metaphor by one speaker may not be so experienced by another; why metaphors, even very conventional ones, seem to receive so many different and varied interpretations.

This approach avoids, in short, an overly simplifying and overly reifying treatment of the knowledge with which speakers go about in their language games. As Frege once pointed out, in a radical refusal of Aristotele's idea that "the affections of the soul" are the same for everyone, the knowledge of individuals is not uniform at all - "a painter, a horseman and a zoologist will probably connect different ideas with the name 'Bucephalus'". ${ }^{10}$ The Wittgensteinian approach I am suggesting here is sensitive to Frege's suggestion with respect to this point, even though it is, for obvious reasons, incompatible with this author's objectivist platonism.

But how exactly does the view of metaphor as the practice of intercrossing language games allow us to respect the heterogeneous character of metaphorical meaning and meaning in general? Well, the practice of intercrossing language games can only be carried out if the language games involved are indeed recognizable as different language games in a given community, in a given situation. Now, this recognition is not at

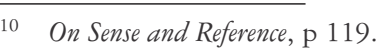


all uniform: it is subject to all sorts of contingent factors - social, cultural, historical, biographical, contextual, and so on. So, to give just one example, borrowed from E. Kittay, the Homeric phrase "rosy-fingered dawn" is likely to have a different metaphorical/literal import for the contemporary reader and for the ancient Greek, who believed the dawn to be a goddess, humanlike in form (cf. Kittay 1987:16; pace Turner, 1989). Thus conceived, metaphors are, as Kittay says, "always relative to a set of beliefs and to linguistic usage which may change through time and place - they are relative to a given linguistic community" (1987:20). The same line of reasoning applies mutatis mutandis to the recognition of novel metaphors as opposed to old ones.

To acknowledge the contingent nature of the oppositions between the metaphorical and the literal, and between novel and old metaphor, is not, however, to say that these oppositions are illusory or have no point. We do, after all, seem to draw these distinctions, in at least many cultures throughout the world. So there is obviously a point in them, even if they do not amount to the kind of "superlative" distinction that, as we have seen, is absent from human conceptual systems. Hence, nothing prevents us from describing these intercrossing language games, and from calling some of them conventional or old metaphors and others novel or unusual metaphors, provided that we do not think of these attributes superlatively. If we conceive of these descriptions as objects of comparison in the Wittgensteinian sense outlined above, they can indeed be very illuminating. Keeping in mind that these descriptions will always be an order - and not the order - in our knowledge of language and human affairs, they can indeed give us insight into the legacy of our culture and into the alternatives it offers.

The characterization of novel metaphors as unusual or unexpected intercrossing language games must be understood, thus, against the background of all the aspects of Wittgenstein's perspective that were highlighted above. I would like to remark, finally, that this characterization accommodates yet another valuable insight, namely the classical idea that metaphors that strike us as unusual or alien to our established conceptual systems may yield some sort of special cognitive gain (Cf. Black 1993, Ricouer 1992; Levin 1988). Intercrossing language games that are taken as unusual or novel may indeed be associated with a special repercussion that was once very aptly described by S. Cavell (without reference to 
metaphor) as follows: they may give me "the occasion to confront the culture with itself" [...], "to throw myself back upon my culture, and ask why we do what we do, judge as we judge, how we have arrived at this crossroads" (1996:45).

\section{Concluding remarks}

In the preliminary exploration that was carried out in this paper, I hope to have demonstrated that the adoption of a Wittgensteinian perspective on language and meaning opens the possibility of reconciling valuable insights offered in three seemingly excluding approaches to the issue of novel metaphor and conceptual stability. Being a non-foundational approach that defends a non-superlative view of the stability and transparency of human conceptual systems, it does justice to the deconstructionist qualms about the reliability of any absolute line dividing metaphorical and literal or old and novel in metaphor. Without falling prey of anti-theoretical nihilism, however, it also does justice to the wealth of generalizations and empirical findings on metaphor offered in the cognitive tradition, by taking them to be potentially instructive objects of comparison in the description of patterns and alternatives in our cultural heritage. Without, however, endorsing the relative disregard for the heterogeneous nature of human meaning that seems to characterize cognitive foundational approaches, the Wittgensteinian viewpoint discussed here favors also the classical idea that the meaning of metaphors is ultimately irreducible, that it is dangerous, as M. Black warned us, to postulate standard a priori responses to any given metaphor. Indeed, the view outlined here radicalizes this position, meant originally to apply only to metaphors that are taken to be novel, by extending it to conventional metaphors as well. Finally, the approach discussed here also accommodates the classical idea that metaphors that strike us as unusual or alien may be associated with possibility of a special kind of cognitive gain.

The key to the Wittgensteinian alternative suggested here is, as I hope to have made clear, renouncing the representationalist view of metaphor as an autonomous conceptual entity with inherent properties, in favor of conceiving it as part of a form of life - as the culturally determined practice of intercrossing language games, a practice with many different possible repercussions and degrees of visibility. 
The full implications of adopting this viewpoint are of course far from covered in this study, which, as said before, explores the topic on a preliminary basis. Among the many important issues that were left untouched here, two should be explicitly acknowledged. Firstly, nothing was said about the psychological import of the Wittgensteinian approach. With respect to this, I would like to remark only that, being clearly a nonpsychological approach, it is by no means an anti-psychological one (cf. PI $\S 308$; Baker \& Hacker, 1980:321-346). Secondly, nothing was done here to deal with the "weed" of epistemic relativism, which surely insinuates itself with the talk of "an order in our knowledge; not the order". As I shall not be able to show in detail here, the Wittgensteinian position may indeed favor a special version of conceptual relativism, but this does not go hand in hand with an epistemic relativism of the "anything goes" type (cf. Glock, 1996:48-50; 126-7; 281-2).

E-mail: lena@rdc.puc-rio.br

\section{REFERENCES}

Arrojo, R. e Rajagopalan, K. 1992. "Noção de literalidade: metáfora primordial" In Arrojo, R. O signo desconstruído. São Paulo: Pontes

Baker, G.P. \& Hacker, P.M.S. 1980. An analytical Commentary on the Philosophical Investigations Oxford: Basil Blackwell, vol. 1. . 1984. Language, Sense, and Nonsense Oxford: Blackwell.

Black, M. 1993. "More about Metaphor" In Ortony (ed.) (1993), pp. 1941.

Cavell, S. 1979. The Claim of Reason. N. York: Oxfor University Press. . 1996. The Cavell Reader .Cambridge MA: Blackwell.

Culler, J. 1989. "Paul de Man's Contribution to Literary Criticism and Theory" In Cohen, R. (ed.) The Future of Literary Theory. N. York: Routledge.

De Man, P. 1992. "Epistemologia da metáfora" In Sacks, S. (ed.) Da Metáfora, São Paulo: Educ/Pontes.

Derrida, J. 1972. "La Mythologie Blanche" In Marges de La Philosophie Paris:Minuit, p. 247-324.

. 1978. "Le retrait de la métaphore" In PoEsie, 7, p. 106-126.

Fogelin, R.J. 1994. «Metaphors, Similes and Similarity» In HintikKA (ed.) Aspects of Metaphor Dordrecht: Kluwer Academic Publishers (1994). 
Frege, G. 1974. "On Sense and Reference” In Zabeeh, F.; Klemke, E.D. \& Jacobson, A. Readings in Semantics Urbana: University of Illinois Press.

Gibis, R. 1994. The Poetics of Mind. N. York: Cambridge University Press. Glock, H-J. 1996. A Wittgenstein Dictionary. Oxford:Blackwell.

Grady, J. E., Oakley, T. \& Coulson, S. 1997. "Blending and Metaphor" In Gibbs, R. W. Jr. \& Steen, G. J. (eds.) Metaphor in Cognitive Linguistics Amsterdam:John Benjamins.

HARRIS, R. \& TAYLOR, J.T. 1989. Landmarks in Linguistic Thought I London: Routledge.

Johnson, M. 1987. The Body in the Mind: the Bodily Basis of Reason, Meaning and Imagination Chicago: University of Chicago Press.

KitTay, E. 1987. Metaphor, Oxford: Clarendon Press.

Lakoff, G \& Johnson, M. 1980. Metaphors we Live By, Chicago: The University of Chicago Press 1999. Philosophy in the Flesh. New York: Basic Books. .2002. "Why embodied realism is required" In Cognitive Linguistics, vol. 13-3, New York: Mouton de Cruyer, pp. 245-263.

Lakoff, G. \& Turner, M. 1989. More than Cool Reason - A field Guide to Poetic Metaphor, Chicago: The University of Chicago Press.

Lakoff, G 1987. Women, Fire, and Dangerous Things. Chicago: The University of Chicago Press.

. 1993. Contemporary Theory of Metaphor In ORTONy (ed.) (1993).

Levin, S. 1988. Metaphoric Worlds. New Haven: Yale University Press.

Mac Cormarc, E.R. 1990. A Cognitive Theory of Metaphor, Cambridge, MA: The MIT Pres.

Martins, H. 1999. "Metáfora e polissemia no estudo das línguas do mundo: uma aproximação não representacionista" Tese de Doutorado, Rio de Janeiro: UFRJ.

Mulhall, S. 1996. The Cavell Reader .Cambridge MA: Blackwell.

Nietzsche, F. 1978. Sobre verdade e mentira no sentido extra-moral. Trad.Rubens Rodrigues T. Filho. Coleção Os Pensadores. São Paulo: Abril Cultural.

Ortony, A. (Ed) 1993. Metaphor and Thought . Cambridge: CUP.

Perloff, M. 1996. Wittgenstein's Ladder.Chicago: The University of Chicago Press.

Rakova, M. 2002. "The philosphy of embodied realism: a high price to pay?" In Cognitive Linguistics, vol. 13-3, New York: Mouton de Cruyer, pp. 215-244.

Ricoeur, P 1992. "O processo metafórico como Cognição, Imaginação e Sentimento” In Sacks, S. (ed) In Da Metáfora, São Paulo: Educ/Pontes. 
1975. The Rule of Metaphor: Multidisciplinary Studies in the Creation of Meaning in Language. Toronto: Univesrsity of Toronto Press.

RoRTY, R. 1991. Objectivism, Relativism and Truth. - Philosophical Papers, Vol. 1. Cambridge: Cambridge University Press.

Solomon, R. C. 1988. Continental Philosophy since 1750 - The Rise and Fall of the Self.

SweETSER. 1991. From Etymology to Pragmatics: Metahorical and Cultural Aspects of Semantic Structure, Cambridge: CUP.

Turner, M. 1996. The Literary Mind New York: Orford University Press.

Wittgenstein, L. 1953. Philosophical Investigations Nova York: Macmillan 1958. The Blue and the Brown Books Oxford: Blackwell 1969. On certainty Oxford:Blackwell. 